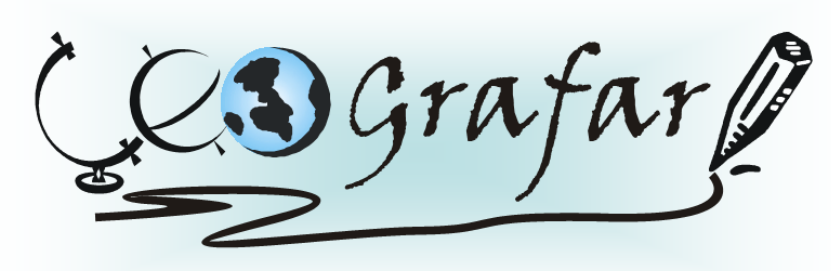

Revista Eletrônica do Programa de Pós-Graduação em Geografia - UFPR

\title{
CIDADES MÉDIAS: PERCURSOS CONCEITUAIS E REALIDADE - O EXEMPLO DE FOZ DO IGUAÇU-PR
}

\author{
CLÁUDIA HELOIZA CONTE ${ }^{1}$ \\ TÂNIA MARIA FRESCA ${ }^{2}$
}

\begin{abstract}
RESUMO
O presente trabalho constrói uma discussão sobre a temática de cidades médias, abordando as formas como estas são tratadas e estudadas na atualidade. Apoiados em diversos trabalhos acerca da temática, realiza-se uma discussão das mudanças que ocorreram nas concepções teóricas e metodológicas em tais estudos. Discuti se as políticas urbanas nacionais realizadas durante as décadas de 1970 e 1980, assim como seus resultados e suas avaliações e as atuais abordagens para estas cidades. A partir de então, analisa-se neste artigo a cidade de Foz do Iguaçu enquanto uma cidade média inserida na rede urbana do oeste paranaense.
\end{abstract}

Palavras-chave: cidades médias, rede urbana, Foz do Iguaçu.

\section{MEDIUM SIZED CITIES: CONCEPTUAL PATHWAYS AND REALITY. THE EXEMPLE OF FOZ DO IGUAÇU}

\begin{abstract}
This paper builds a discussion on the subject of medium-sized cities, addressing the ways in which these cities are treated and studied today. Supported in several studies concerning this subject, takes place a discussion of changes that occurred in the theoretical and methodological conceptions in such studies. Discuss wether the national urban policies undertaken during the 1970 and 1980s, as well as its results

\footnotetext{
${ }^{1}$ Mestranda em Geografia pela Universidade Estadual de Maringá. E-mail: claudiaheloiza@yahoo.com.br.

${ }_{2}^{2}$ Professora Doutora do Departamento de Geografia da Universidade Estadual de Londrina.

E-
} mail: Tânia_geografia@yahoo.com.br.
\end{abstract}


and its evaluations. Since then, this article analyzes the city of Foz do Iguaçu as a medium inserted in the west of Parana state's urban network.

Keywords: medium - sized cities, urban network, Foz do Iguaçu.

\section{INTRODUÇÃO}

Quando se discute urbanização brasileira deve-se considerar que, de modo geral é a partir do final do século XIX que ocorre maior intensificação deste processo, mas "[...] foi necessário ainda mais um século para adquirir as características com as quais conhecemos hoje [...]" (SANTOS, 2005, p.22).

Santos (2005) aponta que pouco se alterou na urbanização brasileira até o final do século XIX, e cresceu menos de quatro pontos nos trinta anos entre 1890 e 1920 ( passando de 6,8\% a 10,7\%). Por outro lado, foram necessários apenas vinte anos entre 1920 e 1940 para que essa taxa triplicasse, passando a 31,24\%. Neste sentido, percebe-se ainda que entre os anos de 1940 e 1980, ocorre uma profunda inversão no que diz respeito ao lugar de residência da população brasileira, ou seja, em 1940 a taxa de urbanização era de 26,35\% e na década de 1980 saltou para $68,86 \%$.

No contexto do crescimento da urbanização brasileira, Carlos (1992, p.60) vincula a existência da cidade a seis elementos: "[...] divisão do trabalho, divisão da sociedade em classes, acumulação tecnológica, produção do excedente agrícola decorrente da evolução tecnológica, sistema de comunicação e a certa concentração espacial das atividades não - agrícolas". Ao mesmo tempo deve-se considerar que a cidade assume formas, características e funções em cada uma das distintas etapas do processo histórico. Desta forma, "[...] a cidade seria, em cada época, o produto da divisão, do tipo e dos objetos de trabalho, bem como do poder nela centralizado" (CARLOS, 1992, p.57).

A partir da década de 1970 a rede urbana brasileira passou por intensas transformações, que de acordo com Corrêa (2006) podem ser caracterizadas pela desconcentração, ampliação e diversificação das atividades industriais, com o aparecimento de centros industriais especializados e diversificados; a modernização, 
industrialização e capitalização do campo, com destaque para a constituição de grandes complexos agroindustriais, entre outros.

Deve-se enfatizar a ampliação de uma base técnica associada principalmente as comunicações e aos transportes, que possibilitou a diversificação das interações espaciais. Nesta perspectiva é primordial o reconhecimento dos novos papéis assumidos e desempenhados pelas cidades, cabendo identificar também as novas funções urbanas e as novas interações espaciais que delas derivam. Tais alterações determinam as novas formas de inserção das cidades na rede urbana, alterando desta maneira seus aspectos funcionais e estruturais. Complementando esta idéia, Santos (2005, p.77) afirma que:

\begin{abstract}
A partir dos anos 1970, o processo de urbanização alcança novo patamar, tanto do ponto de vista quantitativo, quanto do ponto de vista qualitativo. Desde a revolução urbana brasileira, consecutiva à revolução demográfica dos anos 1950, tivemos, primeiro, uma urbanização aglomerada, com o aumento do número - e da população respectiva - dos núcleos com mais de 20 mil habitantes e, em seguida, uma urbanização concentrada, com a multiplicação de cidades de tamanho intermédio, para alcançarmos, depois, o estágio da metropolização, com o aumento considerável do número de cidades milionárias e de grandes cidades médias (em torno de meio milhão de habitantes).
\end{abstract}

A partir destas considerações, o presente trabalho enfatizará a sua discussão em torno de um dos pontos característicos deste processo de urbanização ocorrido no Brasil e que tem recebido destaque desde então, ou seja, a temática de cidades médias. Para tanto, o estudo está divido em quatro partes, exclusa a introdução. A próxima delas discute a trajetória dos debates sobre cidades médias; na seqüência a discussão se dá com base nos programas de políticas urbanas realizadas no Brasil. Posteriormente, analisa-se a realidade de uma cidade média - Foz do Iguaçu - PR, e por último constrói-se algumas considerações finais.

\title{
2 CIDADES MÉDIAS: UMA DISCUSSÃO
}

Foi na década de 1950 e principalmente no decorrer da década de 1960, aliado a emergência das preocupações com o desenvolvimento regional e com a tentativa de corrigir os desequilíbrios regionais que as cidades médias surgiram 
como uma 'solução' para os planejadores franceses. Porém, neste período a cidade média ainda não possuía um conceito desenvolvido.

Um conceito de fato surgiu na França, associado às políticas de desconcentração de população e atividades implantadas pelo VI Plano de Desenvolvimento Econômico e Social (1971-1975). Costa (2002, p.104) explicita que entre os principais objetivos do VI Plano, constam "[...] a distribuição mais adequada do emprego, a continuação do desenvolvimento da região Oeste e o reforço das regiões de fronteira [...]".

No âmbito nacional, verifica-se a partir da década de 1950 que, com a intensidade do crescimento demográfico das metrópoles nacionais, que estavam absorvendo uma considerável parte do contingente populacional advindo da zona rural de distintas regiões do país, as então cidades médias passaram a ser o destino de parte dos fluxos migratórios.

$\mathrm{Na}$ década de 1970, como conseqüência do projeto nacional desenvolvimentista continuado pelo governo militar, que baseava-se no desenvolvimento urbano-industrial, mesmo privilegiando as grandes cidades ${ }^{3}$, percebe-se a primeira tentativa de criar políticas para as então cidades médias, considerando a visibilidade que estas tiveram nos planos e políticas de desenvolvimento nacionais. Este assunto será retomado no decorrer deste trabalho.

Para Amorim Filho e Serra (2001), a cidade média era cada vez mais necessária, pois representava uma das alternativas de manutenção do sistema socioeconômico vigente. O mau funcionamento (medido em termos de custos sociais), resultante da concentração exagerada de homens, de atividades e de capitais tinha de ser revertido de alguma maneira, considerando que o mercado não foi capaz de alocar os fatores produtivos de forma mais equitativa em termos espaciais. Neste sentido, as cidades médias representavam 'válvulas de desconcentração' tendo como papel a diminuição dos problemas oriundos da excessiva concentração produtiva, populacional e contradições oriundas da ausência de infraestrutura e serviços coletivos.

\footnotetext{
3 "A estrutura urbana nacional da década de 70 era formada por alguns centros primazes, representados por duas metrópoles de alcance nacional (SP e RJ), poucas metrópoles de alcance regionais, um limitado número de centros intermediários e uma vasta rede de pequenas cidades [...]" (Amorim Filho e Serra, 2001, p.10)
} 
Durante a maior parte da década de 1980 as políticas voltadas às cidades médias foram enfraquecidas, assim como o princípio do planejamento urbanoregional foi esvaziado, dando lugar para políticas públicas mais pontuais e voltadas principalmente para questões menos estratégicas e mais sociais no âmbito regional.

Em meados da década de 1990, a crescente urbanização reflete as grandes transformações advindas da globalização e da territorialização das redes globais. Todo esse processo atinge a rede urbana, colocando desta forma as cidades médias em foco novamente. A partir desta nova configuração e considerando a separação mantida entre as funções de gestão nas metrópoles e de produção nas cidades médias, estas últimas começaram a revelar e realizar outras funções, além daquelas vinculadas a sua inserção em redes urbanas efetuando a mediação entre a metrópole e as pequenas cidades.

Nesta perspectiva, Nogueira e Garcia (2007) colocam que a temática das cidades médias voltou à agenda da discussão no Brasil, haja vista a multiplicação dos centros urbanos desse tipo, adicionado o fato do aumento de sua importância na composição demográfica e os indicadores econômicos do país.

A partir destes apontamentos, cabe mencionar que a designação "cidade média" coloca de imediato a questão referente à sua definição. Um ponto que explica esta dificuldade em conceituar cidades médias encontra-se no fato de a dimensão populacional variar de acordo com a escala de análise. Com base na escala mundial, os valores são consideravelmente distintos, como por exemplo: a Organização das Nações Unidas (ONU) considera como cidades médias aquelas que possuem entre 100 mil e três milhões de habitantes, o VII Congresso Ibero Americano de Urbanismo considerou médias todas as cidades com 20 a 500 mil habitantes, enquanto a Comissão Européia define como sendo cidades médias aquelas que possuem entre 100 e 250 mil habitantes. Bellet e Llop Torne (2007, p.3) são enfáticas ao afirmar que:

Una cuestión de cantidad que no sería muy fácil de delimitar, puesto que, en cada contexto, presentaría rangos completamente distintos. Así una ciudad media o intermedia en Europa se correspondería con una ciudad pequeña y/o muy pequeña en el contexto chino o indio, en que hay un importante número de ciudades que superan fácilmente el millón de habitantes. 
A heterogeneidade de valores mostra-nos a dificuldade em sustentar a definição de cidade média apoiado em critérios relacionados à sua dimensão física e demográfica, assim como realizar estudos comparativos entre países. Neste sentido, Costa (2002, p.109) contribui ao dizer que:

\begin{abstract}
As dificuldades em definir as cidades médias com base em critérios demográficos e funcionais estão associadas a vários fatores sobre os quais importa refletir. Por um lado depende do grau de urbanização e do sistema de povoamento, por outro, depende do próprio conceito de urbano. Fatores como as diferenças na organização político-administrativa e o nível de desenvolvimento econômico e social de cada pais ou região são igualmente importantes, permitindo relevar a necessidade de compreender as diferenças e os contextos regionais em que se inserem as cidades.
\end{abstract}

Amorim Filho e Serra (2001) argumentam ainda, não existir uma idéia consensual do que seriam as cidades médias. Essa ausência de consenso, todavia ocorre no meio técnico - cientifico, onde literalmente não existe uma definição fortalecida de cidade média, uma classificação a qual pudesse ser utilizada ao mesmo tempo por sociólogos, economistas, arquitetos, geógrafos, demógrafos, mesmo que inserida em cada especialidade seja possível alcançar algum acordo sobre a matéria.

Na concepção de Santos (2005) o que definia cidade média há décadas já não satisfaz a atual estrutura socioeconômica, onde uma cidade média suporte a uma determinada qualidade de atividades e serviços os quais são essenciais para atender a uma população superior a 100 mil habitantes. O autor citado defende a idéia de que o limite mínimo para cidades médias seja 100 mil habitantes, porém justificando-o em termos do nível de complexidade da divisão do trabalho e/ou pela diversificação de bens e serviços ofertados localmente. Amorim Filho e Rigotti (2002, p.2) por sua vez, apontam três grandes problemas geográficos e socioeconômicos que estiveram na raiz da preocupação com o tema das médias e pequenas cidades. São eles:

A exacerbação de problemas de desequilíbrios urbano-regionais, cujo tipo clássico foi amplamente descrito na obra de GRAVIER (1958) sobre 'Paris e o deserto francês';

O agravamento das condições de qualidade de vida nas grandes aglomerações urbanas, bem como um aumento acelerado dos problemas sociais ai verificados;

A frágil organização hierárquica das cidades e, obviamente, o fluxo insuficiente das informações e das relações socioeconômicas nas redes 
urbanas da maior parte dos países do mundo, com reflexos negativos sobre o funcionamento dos sistemas político-econômicos.

Diante destas constatações, Amorim Filho e Serra (2001, p.7-8) propuseram uma conceituação mais abrangente e que melhor caracterizasse cidades médias, baseada nos seguintes atributos:

\begin{abstract}
Interações constantes e duradouras tanto em seu espaço regional, quanto com aglomerações urbanas de hierarquia superior;

Tamanho demográfico e funcional suficientes para que possam oferecer um leque bastante largo de bens e serviços microrregional a elas ligado;

Capacidade de receber e fixar os migrantes de cidades menores ou da zona rural $[\ldots]$;

Condições necessárias ao estabelecimento de relações de dinamização com o espaço rural, microrregional que as envolve;

Diferenciação do espaço intra-urbano com um centro funcional já bem individualizado e uma periferia dinâmica [...];

Aparecimento, embora evidentemente em menor escala, de certos problemas semelhantes aos das grandes cidades, como, por exemplo, a pobreza das populações de certos setores urbanos.
\end{abstract}

Bessa (2005) acrescenta ainda que ao critério demográfico devem-se somar aspectos como natureza, intensidade e periodicidade das relações espaciais, o papel como centro de gestão do território e o arranjo espacial da área de influência que comanda, além da análise da gênese e evolução do contexto socioespacial na qual estão inseridas as cidades.

Como comentado anteriormente, as cidades médias não só eram, mas continuam sendo valorizadas como fator de equilíbrio para as redes urbanas de diversos países, principalmente aqueles onde a diferença e/ou distância entre as cidades grandes e pequenas é mais acentuada, como no caso do Brasil. Neste mesmo sentido, outro aspecto bastante relevante diz respeito às funções de relação de intermediação exercidas por elas entre de um lado, as pequenas cidades e de outro as grandes cidades e o meio rural regionais. Bessa (2005, p.275) complementa:

[...] Desta forma, as cidades médias tornam-se nós de interseção e superposição entre horizontalidades e verticalidades, portanto são capazes de manter com regularidade, relações em nível local, regional, nacional e, até mesmo, internacional, o que demonstra a ampliação de seus espaços de relação econômica e uma conseqüente diversificação dos fluxos [...]. 
Verifica-se que tanto a centralidade quanto a intermediação entre escala local e global passam por alterações em diferentes intensidades no contexto do processo atual de reestruturação econômica do capitalismo em escala mundial, que atribui também novos papéis para as cidades médias no processo de reprodução e acumulação do capital ${ }^{4}$.

Entre os papeis atribuídos as cidades médias, o papel articulador e de intermediação tem sido encarado como essencial para a implantação, para o desenvolvimento e para a expansão de eixos e corredores de transportes e comunicações, de redes de diferentes tipos que possuam uma base espacial, assim como de redes muito espaciais como as das tecnopoles. (AMORIM FILHO e SERRA, 2001).

O processo de especialização, seja ele criado internamente ou induzido de fora, transpõe para as cidades médias uma particular funcionalidade, que ao mesmo tempo é diferenciadora e integradora, podendo desta forma estar associado às novas demandas do campo, a implantação de atividades industriais, como reflexo da reestruturação e desconcentração industrial, assim como a criação de formas alternativas de atividades advindas das elites locais, na maioria das vezes ligadas ao segmento terciário, e com menor freqüência ao segmento industrial.

Sendo assim, Nogueira e Garcia (2007, p.63) colocam que "[...] as cidades médias estão se tornando, dado o ritmo de seu crescimento, o lugar de concentração da técnica e do trabalho intelectual, atividades necessárias para o desenvolvimento da economia de sua região, de sua hinterlândia." Assim colocado, cabe agora discutir os programas de política urbana que deram ênfase as cidades médias no âmbito nacional.

\footnotetext{
${ }^{4}$ Neste sentido, Bessa (2005, p.274-275) afirma que “[...] as cidades médias passam a abrigar variadas formas de capitais, inclusive com a entrada de capital internacional, sugerindo maior articulação com os circuitos do capitalismo mundial á medida que representam novas áreas de atração de investimentos internacionais, e a demandar serviços especializados que incorporam os últimos avanços tecnológicos, a exemplo de consultoria, propaganda, financeiros, entre outros".
} 


\title{
3 PROGRAMAS DE POLITICA URBANA NACIONAL
}

No Brasil, durante as décadas de 1970 e 1980 falar de cidades médias significava falar de política urbana nacional enquanto política pública. De acordo com Steinberger e Bruna (2001), os programas de maior destaque e/ou notoriedade foram: o item "Política de Desenvolvimento Urbano" do capitulo Desenvolvimento Urbano: Controle de Poluição e Preservação do Meio Ambiente do II PND e o Programa de Cidades de Porte Médio. Estes serão, portanto os programas os quais trabalharemos neste capitulo.

O item "Política de Desenvolvimento urbano", do II PND é considerado como marco temporal da primeira política urbana nacional do Brasil. A sua proposta foi elaborada com base nas seguintes questões:

\begin{abstract}
A velocidade acelerada do processo de urbanização que gerou uma sociedade predominantemente urbana;

O desequilíbrio do sistema urbano com a metropolização prematura, a proliferação de grandes aglomerações urbanas e a pulverização de pequenas cidades, sem um número de cidades médias para dar equilíbrio ao conjunto, além de uma distribuição espacial concentrada no litoral, e;

As cidades como núcleos concentradores de riqueza, mas como locais onde os problemas urbanos assumiam grandes dimensões, a exemplo da desigualdade na distribuição dos equipamentos sociais urbanos. (STEINBERGER E BRUNA, 2001, p.43-44).
\end{abstract}

O objetivo definido foi o de promover uma melhor estruturação do sistema urbano com a intensificação da eficácia das funções exercidas pelas cidades e o acréscimo dos padrões de urbanização e qualidade de vida. Para tanto, seria necessária a implantação de regiões metropolitanas; a identificação das funções a serem cumpridas pelas metrópoles nacionais e regionais; e a definição de pólos secundários. Foram apontadas como estratégias regionais a promoção da urbanização das áreas de ocupação recente das regiões Norte e Centro-Oeste, a dinamização da base econômica das metrópoles regionais do Nordeste, a ordenação do sistema urbano da região Sul e a desconcentração intra-regional na 
região Sudeste. As cidades de porte médio faziam parte em todas as estratégias regionais ${ }^{5}$.

Fica evidente na política urbana do II PND que a sua proposta era contraditória a economia de mercado da época, já que esta privilegiava a concentração de investimentos nos grandes aglomerados urbanos. Com o intuito de conciliar esta contradição, o plano propunha favorecer a implantação de pólos secundários - as cidades de porte médio, que utilizariam das vantagens das aglomerações existentes, concomitantemente serviriam como base para uma estruturação de apoio a constituição de um sistema urbano nacional de maior equilíbrio.

Contrariamente a Política Urbana do II PND, a Política Urbana do último governo da ditadura militar indicou dois programas estratégicos; o de regiões Metropolitanas e de Capitais e o de Cidades de Porte Médio. O programa de cidades de porte Médio vigorou por dez anos, sendo considerado o ano de 1976 como o marco inicial e 1986 a data de encerramento do programa.

Durante a primeira política urbana do programa, as cidades médias foram conceituadas como aquelas cidades que, considerando a sua posição geográfica, população, importância socioeconômica e função dentro da hierarquia urbana da macrorregião e do país, constituíam-se em centros de grande valor estratégico no que concerne ao desenvolvimento regional e também para uma rede urbana mais equilibrada no que envolvesse política de organização territorial. Já na segunda política urbana, o conceito de cidades médias foi baseado nas funções de desconcentração e dinamização.

De acordo com Steinberger e Bruna (2001, p.53) "[...] o programa envolveu 140 cidades, distribuídas pelas cinco macrorregiões, que contavam com uma

\footnotetext{
${ }^{5}$ No Sudeste preconizou-se induzir a descentralização das atividades produtivas das regiões de São Paulo e do Rio de Janeiro para centros periféricos de médio porte. Complementarmente, propôs-se a desconcentração intraregional com atuação preferencial sobre os núcleos urbanos com mais de 50 mil habitantes; no Sul a atuação preferencial seria dirigida aos centros urbanos com população superior a 50 mil habitantes; no Nordeste a prioridade era 0 crescimento das atividades produtivas e a melhoria da infra-estrutura e dos equipamentos sociais nas capitais dos estados e nos pólos regionais alem da dinamização dos núcleos urbanos regionais que exercessem ou viessem a exercer funções de polarização do desenvolvimento regional; e no Norte e CentroOeste previa-se apoiar a dinamização das funções urbanas de capitais dos estados e de outras cidades estrategicamente selecionadas. (STEINBERGER e BRUNA, 2001, p.44)
} 
população total de 13,5 milhões de pessoas residentes nas sedes dos municípios". O programa alcançou desde cidades com população menor que 50 mil habitantes e grau de urbanização em torno de $50 \%$ até outras com população em torno de 600 mil habitantes e com grau de urbanização superior a $90 \%$.

No ano de 1984, a FAU/USP realizou uma pesquisa com o intuito de avaliar a qualidade e a empregabilidade de ambos os programas. As conclusões destas avaliações mostraram que a eficácia do programa foi desprezível, já que os resultados obtidos ficaram muito distantes do esperado. Não foi possível estimular o desenvolvimento das potencialidades locais e regionais, mesmo porque as ações do programa tiveram impacto pontual nas condições de vida urbana, ou seja, restritas as áreas intra-urbanas, não sendo possível alterações significativas nas perspectivas econômico e social como foi planejado. Como mérito a FAU/USP pontuou a inserção do aproveitamento do potencial regional e local das cidades médias como uma questão nacional. Dentro deste contexto Steinberger e Bruna (2001, p.63-64) explicitam que:

[...] se as cidades médias são atualmente uma realidade, por certo essa condição não foi decorrente do programa, uma vez que o mesmo constituiu em uma experiência espacialmente fragmentada. [...] Entretanto, é preciso considerar que, na época, as regiões metropolitanas imperavam como os locais mais atraentes para a localização de qualquer atividade econômica, e falar em cidades médias era bastante utópico.

Apesar de tais programas não terem alcançado plenamente seus objetivos, nada mostra até o momento atual que as cidades médias venham a ser objeto de atenção ou preocupação por parte do governo, como ocorreu de fato no período entre 1975 e 1986.

A próxima parte do estudo será dedicada à análise da cidade de Foz do Iguaçu enquanto uma cidade média inserida na rede urbana do oeste paranaense. 


\section{FOZ DO IGUAÇU: UMA CIDADE MÉDIA DO OESTE PARANAENSE}

Foz do Iguaçu é um exemplo evidente da importância crescente das cidades médias no Brasil, pois a partir da década de 1970 com o início da construção da Usina Hidrelétrica de Itaipu apresentou um crescimento e um considerável desenvolvimento econômico, caracterizado principalmente por aquilo que Bessa (2005) considerou de produção não - material, ou seja, comércio e prestação de serviços. No decorrer da década de 1970 e principalmente na década seguinte, ocorreu a implantação de infra estrutura, especialmente as de transportes e comunicações.

Tal materialidade possibilitou a expansão das funções urbanas centrais, o que de certa forma permitiu maior complexidade funcional para a cidade. Foz do Iguaçu não se opôs a expansão de um meio técnico - cientifico - informacional e a conseqüente implantação de objetos técnicos, ou seja, ao acréscimo estrutural e funcional de componentes ligados á modernização das referidas infraestruturas econômicas, como os já mencionados transporte e comunicação, além do segmento energético. A implantação destes colaborou no processo de desenvolvimento das atividades econômicas realizadas na cidade, principalmente aquelas ligadas ao comércio, tanto atacadista como varejista e também a prestação de serviços.

Foz do Iguaçu possui uma localização singular, pois neste sentido além de cumprir funções enquanto cidade média inserida na rede urbana do oeste paranaense constitui-se em um centro na rede da América do Sul, fato este que coloca a cidade como parte integrante de duas redes urbanas. Inserir-se em pelo menos duas redes, é explicado por Corrêa (1997, p. 100) quando afirma que "A complexidade funcional crescente vai traduzir-se entre outros aspectos, no fato de que cada centro situa-se simultaneamente em pelo menos duas redes. Uma constituída por localidades centrais (metrópole, capital regional, centro sub regional, centro de zona, centro local) e outra, menos sistemática e mais irregular, na qual cada centro desempenha um papel singular e /ou complementar a outros centros". 


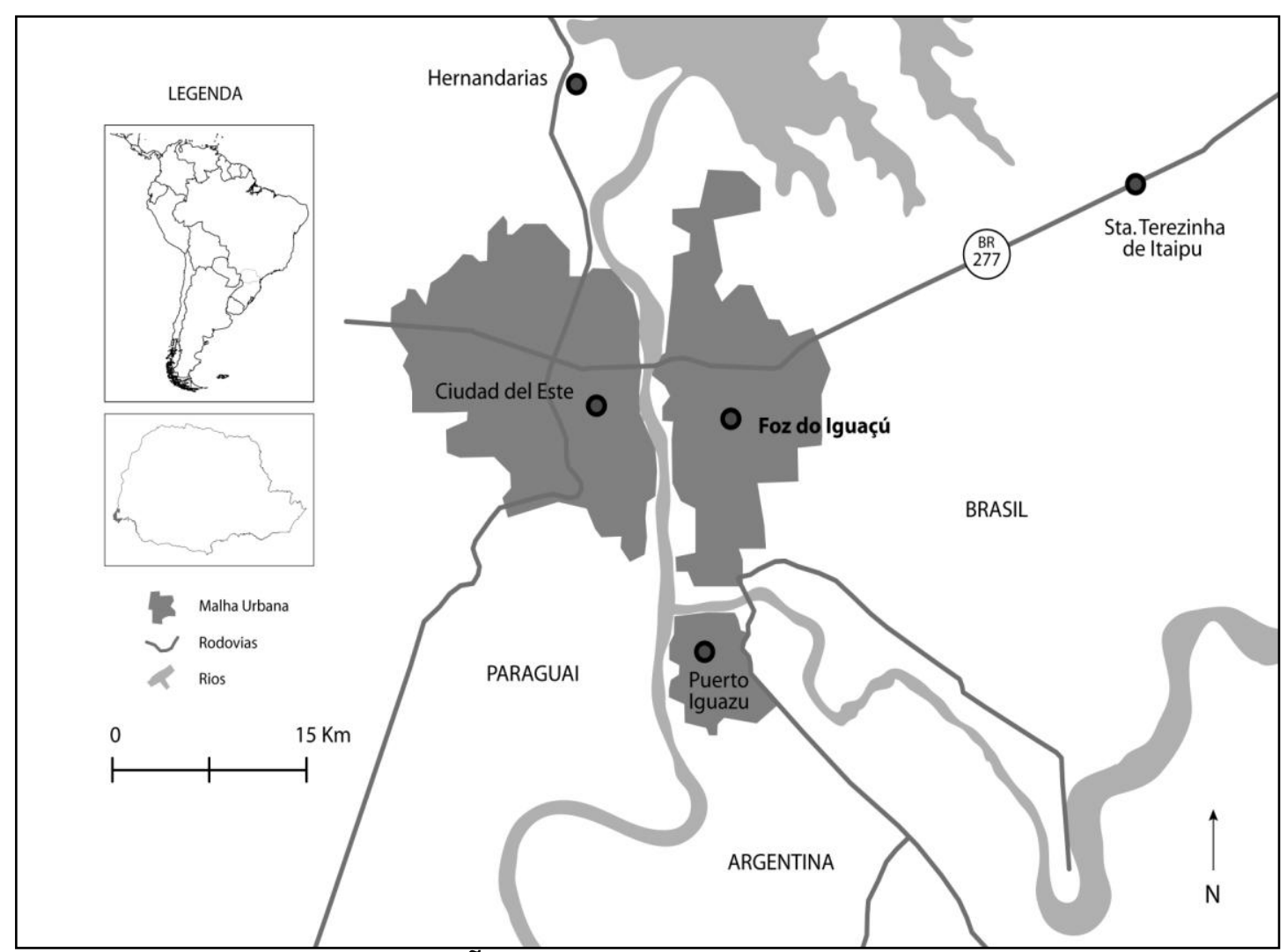

MAPA 1 - LOCALIZAÇÃO DE FOZ DO IGUAÇU

A relação mantida entre Foz do Iguaçu e as cidades de Ciudad Del Este e Puerto Iguazu existem anterior ao período de fundação da cidade, ou seja, 1914. Todavia, esta relação foi fortalecida com o grande crescimento da área de fronteira e de acordo com Roseira (2004) passou a ser definida tanto pela concorrência quanto pela complementaridade. O fluxo comercial entre elas é definido segundo o ritmo das políticas econômicas de cada país, principalmente das políticas monetárias e as variações cambiais entre os três países.

Considerando a forte participação do comercio "ilegal" nas atividades econômicas de Ciudad Del este e a pouca vitalidade de Puerto Iguazu, a cidade brasileira sempre teve um grande poder de atração sobre a população destas cidades, principalmente na venda de produtos como roupas, móveis e alimentação (ROSEIRA, 2004).

Em relação ao sistema de transporte, durante a década de 1960, duas grandes obras viárias foram construídas na região: a rodovia BR 277, que permitiu o acesso da cidade à Curitiba e ao porto de Paranaguá e a Ponte Internacional da 
Amizade (ligando Brasil e Paraguai). De fundamental importância para a integração territorial brasileira, estas obras foram essenciais para que o Brasil alcançasse maior vantagem em relação à atração do porto de Buenos Aires.

No que concerne ao transporte de cargas, Foz do Iguaçu conta com Estação Aduaneira - Porto Seco, administrado pela Eadi Sul Terminal de Cargas Ltda., oferecendo serviços aduaneiros para a efetuação de operações de exportação e importação. Para se ter idéia desta movimentação, basta verificar que no ano de 2010 o porto apresentou a circulação de 143.663 caminhões $^{6}$.

Os fluxos de circulação na cidade são efetuados em uma quantidade particularmente grande por meio do Aeroporto Internacional de Foz do Iguaçu. Através deste aeroporto consolida-se a circulação de cargas e principalmente de pessoas, que além de motivadas pela atividade turística, utilizam o aeroporto para diversas outras atividades econômicas, sendo elas de âmbito local, regional, nacional ou internacional. Neste sentido, verifica-se de acordo com o quadro abaixo, que desde o ano de 2005 o aeroporto vem contando com número crescente de aeronaves e passageiros, cuja média no período 2005-2010 foi de 768.000 passageiros/ano.

\begin{tabular}{|c|c|c|c|}
\hline Ano & Aeronaves & Carga & Passageiros \\
\hline 2005 & 10.909 & 600.387 & 818.512 \\
\hline 2006 & 10.059 & 709.175 & 731.312 \\
\hline 2007 & 10.410 & 969.278 & 721.385 \\
\hline 2008 & 10.878 & 739.922 & 766.444 \\
\hline 2009 & 11.918 & 758.201 & 807.540 \\
\hline 2010 & 15.886 & 810.780 & 1.155 .615 \\
\hline $2011^{7}$ & 3.108 & 147.473 & 266.097 \\
\hline
\end{tabular}

QUADRO 1 - NÚMERO DE AERONAVES, CARGA E PASSAGEIROS NO AEROPORTO DE FOZ DO IGUAÇU-PR: 2005-2011

FONTE: http://www.infraero.gov.br/index.php/br/estatistica-dos-aeroportos.html ORG: A autora

\footnotetext{
${ }^{6}$ Disponível em: http://www.portosenavios.com.br

${ }^{7}$ Dados apenas dos meses de Janeiro e Fevereiro de 2011.
} 
Importante frisar que parte significativa destes passageiros que utilizaram o aeroporto estavam vinculados à atividade turística, cujas origens dos mesmos são as mais distintas em escala nacional e internacional. Esse dado é importante porque insere a cidade de Foz do Iguaçu em outra rede, muita mais ampla que é a da atividade turística, sendo considerada uma das mais visitadas do país. Neste sentido, há que se ressaltar a presença de toda uma série de atividades prestadoras de serviços e comerciais na mesma para atender as mais distintas demandas dos turistas, complexificando funcionalidade da cidade.

Os fixos artificiais ligados aos meios de comunicação também obtiveram uma considerável expansão após a década de 1970, possibilitando desta forma a ligação de Foz do Iguaçu com o restante do país e também do mundo, via equipamentos de transmissão e de recepção, que permitem o estabelecimento de fluxos descontínuos e distantes territorialmente, oferecendo desta forma a cidade e a rede urbana uma considerável fluidez.

Quanto à produção industrial na cidade, esta é modesta tanto em número de estabelecimentos quanto de empregos gerados. Segundo o IPARDES, os estabelecimentos industriais em número de 223 , estão ligados principalmente ao segmento das estruturas metálicas e de madeira.

Por outro lado, ao analisar o número de estabelecimentos ligados ao comércio e serviços (2.428 do comércio varejista; 406 para o atacadista e 538 para os serviços), nota-se outra dinâmica. Isso se deu principalmente após a década de 1970, com a 'chegada' de Itaipu e com maiores investimentos no segmento turístico ${ }^{8}$. Os impactos advindos da força com que o turismo traz a economia da cidade são muitos. Nesta perspectiva, visualiza-se que todas as atividades comerciais da cidade são de alguma forma - direta ou indiretamente envolvidas pelo setor turístico, principalmente o comércio atacadista e varejista. Os setores que possuem ligação estreita com o turismo se sobresaem especialmente pela constante capacidade de geração de empregos diretos.

\footnotetext{
${ }^{8}$ Neste sentido, Bessa (2005, p.270) conceitua cidades médias como sendo: [...] as cidades do interior afetadas pelos programas de modernização da agricultura e da mineração, as cidades voltadas para certos ramos industriais, com dadas especializações produtivas; as cidades afetadas pelo desenvolvimento das atividades do turismo e do lazer, as cidades inseridas no mundo amazônico e nordestino; e por fim, as cidades afetadas pelo projeto do Mercosul.
} 
O grande contingente de visitantes, motivados tanto pelo turismo de compras em Ciudad Del Este como pelo turismo de contemplação nas Cataratas do Iguaçu e Itaipu é um dos quesitos responsáveis pela destacada importância deste setor na economia. É neste sentido que a centralidade exercida por Foz do Iguaçu na rede urbana do oeste paranaense é em muito diferente daquela exercida por Toledo e Cascavel, pois, enquanto estas cidades possuem sua centralidade articulada com a economia baseada na relação entre agroindústria e prestação de serviços, Foz do Iguaçu tem seu destaque mediante função estabelecida na integração entre turismo e prestação de serviços.

Para se ter idéia desta dimensão, segundo o estudo do Paraná Turismo ${ }^{9}$, no ano de 2008 estiveram na cidade de Foz do Iguaçu cerca de dois milhões de turistas, dos quais $75,8 \%$ utilizaram os serviços hoteleiros oferecidos pela cidade. Ainda de acordo com esta pesquisa, no ano de 2008, Foz do Iguaçu contava com 156 estabelecimentos hoteleiros, envolvendo ainda outros serviços como alimentação, saúde, comércio, entre outros.

O setor terciário em Foz do Iguaçu é também expressivo quando se verifica a difusão dos supermercados, shopping Center e pelas novas atividades ligadas á prestação de serviços. Um exemplo disso é o shopping que foi inaugurado em outubro de 2007 e conta com a circulação diária em torno de 6.500 pessoas $^{10}$. Neste sentido, tais segmentos terciários são responsáveis pelo acréscimo tanto quantitativo como qualitativo das interações espaciais que advém da combinação de relações que vinculam-se nas escalas local, regional, nacional e internacional. Essas atividades, segundo Bessa (2005) promovem o surgimento de ocupações e empregos de elevado grau de especialização e, conseqüentemente, uma remuneração mais elevada.

Outro aspecto de importância fundamental para o fortalecimento de Foz do Iguaçu enquanto fornecedor de bens e serviços, diz respeito ao serviço educacional, mais especificamente o ensino superior. Atualmente a cidade conta com três faculdades públicas e oito privadas. Dentre as instituições públicas, a cidade abriga

\footnotetext{
${ }^{9}$ Disponível em: < http://www.fozdoiguacu.pr.gov.br/portal2/home turismo/inventario turistico.asp >

${ }^{10}$ Informação cedida pelo gerente comercial do shopping.
} 
campus da Universidade Estadual do Oeste do Paraná - UNIOESTE, com doze cursos de graduação e um de pós-graduação (mestrado). Conta também com a Universidade Aberta do Brasil - UAB, que tem a sua sede no interior da Itaipu Binacional, mais especificamente no Parque Tecnológico de Itaipu, oferecendo três cursos de graduação e seis especializações. A instituição de ensino mais recente é a Universidade Federal da Integração Latino - Americana - UNILA, que provisoriamente encontra-se instalada no Parque Tecnológico de Itaipu (PTI). Suas atividades tiveram início no segundo semestre de 2009 com a implantação do Instituto de Estudos Avançado (IMEA) e no momento atual oferta seis cursos de graduação.

O número de alunos que utilizam este serviço (ver quadro abaixo) é de aproximadamente 19.732, e deste montante, 8,8\% é proveniente das cidades que fazem parte da região oeste do Paraná. Além disso, 0,47\% são estudantes vindos de Cuidad Del Este - PY e Puerto Iguazu - AR e 1,58\% oriundos de outras localidades.

\begin{tabular}{|l|c|c|c|c|c|}
\hline \multicolumn{1}{|c|}{ Instituição } & Total & $\begin{array}{c}\text { Foz do } \\
\text { Iguaçu }\end{array}$ & $\begin{array}{c}\text { Região } \\
\text { Oeste/PR }\end{array}$ & $\begin{array}{c}\text { Puerto Iguazu/AR e } \\
\text { Ciudad Del Este/PY }\end{array}$ & $\begin{array}{c}\text { Outras } \\
\text { localidades }\end{array}$ \\
\hline $\begin{array}{l}\text { Anglo } \\
\text { Americano }\end{array}$ & 1.234 & 884 & 350 & - & - \\
\hline Cesufoz & 1.215 & 966 & 249 & - & - \\
\hline UAB & 850 & 648 & 153 & - & 49 \\
\hline UDC & 3.500 & 3.083 & 398 & - & 19 \\
\hline Uniamérica & 2.229 & 1.963 & 258 & - & 08 \\
\hline UNILA & 205 & 57 & - & $90^{\text {iil }}$ & 58 \\
\hline Unifoz & 433 & 390 & 43 & - & - \\
\hline UNIOESTE & 1.455 & 982 & 295 & 01 & 177 \\
\hline Total & 19.732 & 8.973 & 1.746 & 91 & 311 \\
\hline
\end{tabular}

QUADRO 2 - NÚMERO DE ALUNOS DE ENSINO SUPERIOR E ORIGEM EM FOZ DO IGUAÇU: 2010

FONTE: Pesquisa de campo realizada em outubro de 2010.

i Compreendido pelas cidades: Santa Teresinha de Itaipu, São Miguel do Iguaçu, Medianeira, Matelândia, Itaipulândia, Missal, Santa Helena, Toledo, Marechal Candido Rondon, Serranopolis do Iguaçu, Céu Azul, Corbélia, Assis Chateaubreand, Cafelândia, Ramilândia e Jesuítas.

ii Compreendidas por - Paraná: Maringá, Francisco Beltrão, Engenheiro Beltrão, Nova Santa Rosa, Ubiratã, Realeza, Umuarama, Paranavaí, Cianorte, Palotina, Chopinzinho, São Jorge do Oeste, Marmeleiro, Cafeara, Santo Antonio do Sudoeste, Pranchita, Perola do Oeste, Nova Aurora, Assai, Quedas do Iguaçu, Palotina, Grandes Rios, São João, Santa Fé, Ponta Grossa, Pato Bragado, Dois Vizinhos, Alvorada do Sul, Ivaporã, Nova Aurora, Curitiba, Apucarana, Arapongas, Bom Sucesso do Sul, Nova Londrina, Cruzeiro do Oeste, Pinhão, Araruna, Itapejara do Oeste, Santo Inácio. São Paulo: São Paulo, Ribeirão Preto, Campinas, Assis, Ourinhos, Marília, Lorena, Presidente Prudente. Santa 
Catarina: São Miguel do Oeste, Ponte Serrada, São Lourenço do Oeste, Dionísio Cerqueira. Demais Localidades: Lucas do Rio Verde/ MT, Navirai/MS, São Gabriel do Oeste/MS, Panambi/RS, Iporã/ GO, Rio de janeiro/RJ, Divinópolis/MG, Juiz de Fora /MG, Campina Grande/PB, Belém/PA, Jequié/BA, Campo Grande/MS, Três Lagoas/MS, Cuiabá/MT.

iii Neste caso especifico são estudantes do Paraguai, Argentina e Uruguai.

Os elementos até aqui mencionados favorecem a implantação e expansão da população, das atividades terciárias, principalmente aqueles ligados ao meio técnico -cientifico - informacional.

Foz do Iguaçu conta atualmente com uma população total de 256.081 mil habitantes, dos quais 253.950 são urbanos (IBGE, 2010) colocando-a como a sexta maior cidade do estado em número de habitantes.

\section{CONSIDERAÇÕES FINAIS}

A cidade e por extensão a rede urbana, independente do tamanho que possua, "[...] apresenta formas repletas de fixidez e, neste sentido, apresenta uma relativamente grande capacidade de refuncionalização" (CORRÊA, 2006, p.280). Através desta e da continuidade do processo de criação de novas funções e suas correspondentes formas - característica das formações espaciais capitalistas - a cidade e também a rede urbana sofrem reatualizações.

Em contrapartida, para que determinada localidade seja interessante sob a ótica de investimentos de capitais em diversas atividades, mas especialmente as terciárias, há necessidade explicita de certa densidade de consumidores. Nesta perspectiva, as cidades médias apresentam-se como espaços oportunos para alocação destes investimentos, mediante seu papel no que diz respeito à oferta de bens e serviços aos habitantes de sua área de influência. Este processo reforça o papel das cidades médias enquanto espaços de consumo tanto locais como regionais, reforçando também a intermediação e a centralidade destas cidades.

Neste contexto, são vários os fatores que colocam Foz do Iguaçu como uma importante cidade média do oeste Paranaense e também da América do Sul. A centralidade regional é exercida inicialmente em uma rede urbana relativamente pequena já que envolve pequeno número de cidades em sua área de influência direta. Mas inclui além daquelas presentes no território nacional, aquelas 
adjacentemente localizadas no Paraguai e Argentina, ofertando bens e serviços dos básicos até aqueles de maior complexidade. Foz do Iguaçu "[...] é um importante nódulo da rede territorial sul-americana" (ROSEIRA, 2006, p.1) na medida que congrega elementos centrais de conectividade e circulação de uma integração territorial continental. A tríplice Fronteira exerce um papel sem precedentes para esta cidade, com uma influência única na rede urbana do oeste paranaense e também da America do Sul. Mas sua centralidade ainda é exercida através de um conjunto e atividades voltadas ao turismo, cuja escala é nacional e internacional.

\section{BIBLIOGRAFIA}

AMORIM FILHO, Oswaldo B; SERRA, Rodrigo Valente. Evolução e Perspectivas do papel das cidades médias no planejamento urbano e regional. IN: ANDRADE, T.A; SERRA, R.V (orgs). Cidades médias brasileiras. Rio de Janeiro. IPEA, 2001.

AMORIM FILHO, Oswaldo. B; RIGOTTI, José Irineu. Os limiares demográficos na caracterização das cidades médias. ENCONTRO NACIONAL DE ESTUDOS POPULACIONAIS, 18, 2002, Ouro Preto MG. Anais... Belo Horizonte: ABEP, 2002.

BELLET, S.C; LLOP TORNÉ, J.M. Miradas a otros espacios urbanos: las ciudades intermédias. Scripta Nova. v. 8, n.165, maio 2004. [on line]. Disponível em:< http://www.ub.es/geocrit/sn/sn-165.htm >. Acesso em junho 2010.

BESSA, Kelly Cristine. Reestruturação da rede urbana brasileira e cidades médias: 0 exemplo de Uberlândia (MG). Caminhos da Geografia, v. 24, n.16, p.268-288, out 2005.

CARLOS, Ana Fani Alessandri. A cidade. São Paulo, Contexto, 1992.

CORRÊA, Roberto Lobato. Estudos sobre a rede urbana. Rio de Janeiro. Bertrand Brasil, 2006.

.Construindo o conceito de cidade média. In: SPOSITO, M.E.B.

(org) Cidades médias: espaços em transição, p. 23-33. São Paulo. Expressão Popular, 2007.

COSTA, Eduarda Marques Da. Cidades Médias: Contribuições para a sua definição. Finisterra, Lisboa v. 37, n.74, p.101-128, 2002.

FRESCA, Tânia Maria. A rede urbana do Norte do Paraná. Londrina. Eduel, 2004. 
$\begin{array}{llll}\text { EMPRESA BRASILEIRA DE INFRA-ESTRUTURA AEROPORTUÁRIA. Estatísticas } \\ -\quad \text { Movimento } & \text { operacional. }\end{array}$ HTTP://www.infraero.gov.br/index.php/br/aeroportos> Acesso: abr 2011.

INSTITUTO ESTADUAL DE DESENVOLVIMENTO ECONOMICO E SOCIAL. (Curitiba - PR). Leituras Regionais. Mesorregião Geográfica Oeste Paranaense. Curitiba, 2003.

NOGUEIRA, Marly; GARCIA, Ricardo Alexandrino. A inserção das cidades médias na rede urbana brasileira. Terra plural, v. 1, n.2, p. 61-71, ago/dez, 2007.

OLIVEIRA JUNIOR, Gilberto. Contradições e enquadramentos das cidades médias ao processo de mundialização do capital. Caminhos da Geografia (UFU. On line). v.9, n.25 ,p.140-148. Uberlândia. Março 2008. [on line]. Disponível em < http://www.ig.ufu.br/revista/caminhos.html > Acesso julho 2010.

PREFEITURA MUNICIPAL DE FOZ DO IGUAÇU. Inventário da Oferta turística em Foz do Iguaçu. Disponível em: < http://www.fozdoiguacu.pr.gov.br/portal2/home turismo/inventario turistico.asp>

Acesso: abril 2011.

PULIDO, Nubis. El espacio urbano latino americano y la globalizacion. Emergencia de cidades "intermédias" y nuevos cambios en Venezuela. In: LEMOS, A.I. G; SILVEIRO, M.L (org). America Latina: cidade, campo e turismo. São Paulo: CLACSO, 2006. p-149-159.

ROSEIRA, Antonio Marcos. Foz do Iguaçu: Cidade: rede sul americana. 2006. Dissertação (Mestrado em Geografia Humana) - Programa de Pós - Graduação em Geografia Humana - USP - São Paulo.

SANTOS, Milton. A urbanização Brasileira. 5 ed. São Paulo: Editora da Universidade de São Paulo, 2005.

SERAFINI, Mariana. Em Foz do Iguaçu Porto Seco bate recorde de movimento em 2010. Noticiário cotidiano - Portos e Logística. Disponível em < HTTP: //WWW.portosenavios.com.br/site/noticiário/portos-e-logistica> Acesso: abril 2011.

STEINBERGER, Marília; BRUNA, Gilda Collet. Cidades médias: elos do urbanoregional e do publico - privado. In: ANDRADE, T.A; SERRA, R.V(orgs). Cidades médias brasileiras. Rio de Janeiro. IPEA. 2001.

(Recebido em 13.12.2010. Aceito em 27.04.2011) 